\title{
Applying Bilingual Teaching on Employment-oriented IT Experience Training Program in Nationalities Universities
}

\author{
Shuang Liu \\ College of Computer Science \& Engineering, Dalian Nationalities University, Dalian, China \\ Email: 1s_liaoning@163.com \\ Xizuo Li \\ College of Computer Science \& Engineering, Dalian Nationalities University, Dalian, China \\ Email: xzli@dlnu.edu.cn \\ Li Zuo* \\ College of Economics and Management, Dalian Nationalities University, Dalian, China \\ Email: zuoli@dlnu.edu.cn
}

\begin{abstract}
It is a little difficult to carry out bilingual teaching in employment-oriented IT experienced training program because of its strong practicality and rapid development. How to keep pace with technology development and adopt effective bilingual teaching method and approach cultivating compound international talents of software development required by society, and how to utilize auxiliary network teaching platform improving students' study independence is the basic target of bilingual reform for the course. Based on summarization of training contents and advantages in software companies and experiences of the first experimental project in Dalian Nationalities University, a feasible training system is put forward. Combined with bilingual teaching experiences of teachers in course group in New Zealand, flexible and variable teaching methods are adopted in order to improve students' study enthusiasm. And students are guided to complete regular software development based on experience training program of software companies in practice teaching. The purpose of this system is to enhance students' professional skill training, improving students' English expression skills of speaking and writing, developing students' project practical ability and communication and expression ability.
\end{abstract}

Index Terms - bilingual teaching, employment-oriented, international talents, experience training, employment competence

\section{INTRODUCTION}

With the development of computer network and information technology, talents demand for international Web application development is increasing rapidly. But graduates with computer major are often troubled with little working experience and poor English expression ability, which leads to unsatisfied employment rate (Collins, 2006). Most international software companies put much emphasis on language application ability and practical experience in their personnel recruitment, so it is necessary to carry out bilingual professional project training program before the seniors' graduation. Now many software companies have set up specific training program for graduating students with English-bilingual or Japanese-bilingual. To obtain more profits, their tuition charge is very expensive. For students coming from minority areas with economic backwardness, they can't afford extra tuition fee to come close to the employment threshold. Moreover, training contents of the companies are always the integration of several courses with more practice exercising and faculty-student ratio is too high. To solve this problem, nationalities universities can set up bilingual experience training curriculum to reduce students' economic burden. Furthermore, the training program can improve seniors' employment competence and make them fit their future work more rapidly.

Many software institutes have tried experience training program (Qin, 2007; Collins, 2007), but there are three shortages. First, most students from the independent college are short of learning subjective initiative and the learning effect is not satisfied. Second, all students must participate in the training, which leads to the result that only a small proportion can complete the whole project and some students with poor fundamental knowledge can't follow the scheduled training process. Third, many training teachers don't have the working experience in software companies.

Based on the summarization of training experiences in software companies and shortages of training program in the independent colleges, we carried out the first experimental project in Dalian Nationalities University in September,

* corresponding author 
2009 and second bilingual training program in September, 2010. The detailed implementation plan, training methodology and teaching organization are discussed in the following sections.

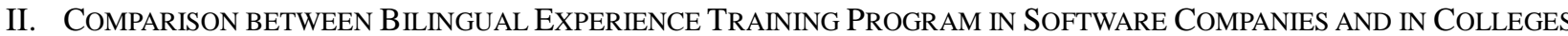

\section{A. Bilingual Experience Training Program in Software Companies}

Seniors have no pressure before they realize the serious employment situation and are short of learning motivation. Bilingual experience training program can force them to focus on reviewing professional knowledge, improving language application ability and adapting to the working environment with high pressure. Certainly there are many advantages of bilingual experience training program in software companies such as the practical project experience, regular bilingual documents of software development, real working environment, training experience and excellent training tutors. But profit is the purpose of training in software companies, so there are many limitations of bilingual experience training program in Software Company for students. We summarize as follow:

(1) Bilingual teaching is carried out by professional English or Japanese teachers. Lack of project development experiences and too much emphasis put on language itself, students will find it difficult to put language study into software development process.

(2) Base on the cost, one class consists of nearly 60 to 70 students, which means students must rely on themselves, not tutors. It is better to have a class not more than 30 students for bilingual teaching.

(3) Teaching resources are limited in the classroom and flash memory disk is forbidden. Students can't copy their codes or documents, much less review in their own computers.

(4) Web resources are limited or even forbidden. So students can't get any reference material to help them understand the teaching content.

\section{B. Bilingual Experience Training Program in Universities}

Education of universities put more emphasis on teaching quality than profit. The purpose of high education is to culture the competitive and high quality graduates. In comparison with software companies, there are many advantages of bilingual experience training program in universities for students, which are summarized as follow.

(1) Project tutors carried out bilingual teaching in the whole experience training program. They adopt communicative teaching methods to improve students' capability of expressing professional knowledge in listening, speaking and writing.

(2) Web resources are open and students can get many help from the web. Teaching resources are open and can be accessed in the multimedia computer room or dormitories. Students can copy courseware and sample codes and save any code fragment or document in their computers.

(3) Teaching is students-centered. One teaching class has 30 students at most. So tutors can give guidance to any student in training. Study pressure put on the students is little by little until they realize the serious employment status.

\section{BILINGUAL EXPERIENCE TRAINING PROGRAM IN DALIAN NATIONALITIES UNIVERSITY}

In September, 2009, we carried out the first experimental project for seniors of grade 2006 with computer science major (Liu, 2010). From July to August, 2010, authors attended a bilingual training program in New Zealand. The training organizer, Edenz Colleges (Edenz Colleges, 2010), adopted a teaching method called communicative teaching methods, which we adopted in our subsequent training program. In September, 2010, we carried out the second bilingual training program for seniors of grade 2007. From the implementation process to teaching approaches, we tried our best to practice and find the best solutions. Introducing communicative teaching methods into bilingual training process, we discussed these issues in the following sections in detail.

\section{A. Implementation Process}

There are two stages of our training program, that is, preparation stage and practical project training stage. The first preparation stage is showed in Fig.1.

In the step of students' selection, we choose some qualified candidates based on English test and programming test in computers because not all students can follow the whole training process. To get enough guidance for each student, each teaching class consists of 30 members at most. For these selected students, the step of synopsis explanation of fundamental knowledge is the same. Students have learned the needed knowledge independently, but they can't relate them together to solve a problem. Functions of this step are to master key idea of the knowledge and learn to solve one problem with integrated knowledge points. In the step of framework explanation, tutors introduce Struts1, Struts2 and Hibernate for students with better fundamental knowledge and introduce only Struts1 for students with average fundamental knowledge. Similar to this, students with better fundamentals practice the small item with integrated frameworks and students with average fundamentals practice the small item with Struts1 only. After reviewing the necessary fundamental knowledge, it is time to start the next practical project training process. Here, we introduce one idea of introducing games into theory teaching from communicate teaching methods. For example, in software engineering teaching (Roger, 2005), life cycle of software development is divided into different parts, and students are 
instructed to rearrange these parts into one complete flow chart. Using this way, it will be much easier for students to accept new theory than presentation directly. If students can participate in lesson teaching process, they will be interested in what are studying.

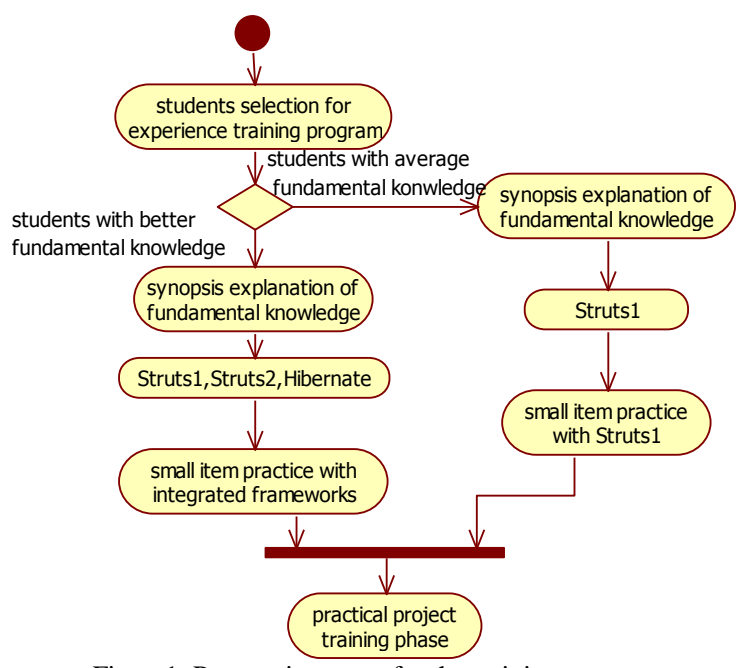

Figure1. Preparation stage for the training program.

Bilingual practical training process is very important for each student. In this process, they not only learn how to express professional knowledge in English, but also learn how to develop software based on regular document specifications. Flowchart of the practical project training process is too long, so we decompose it into two parts. The first part is shown in Fig.2.

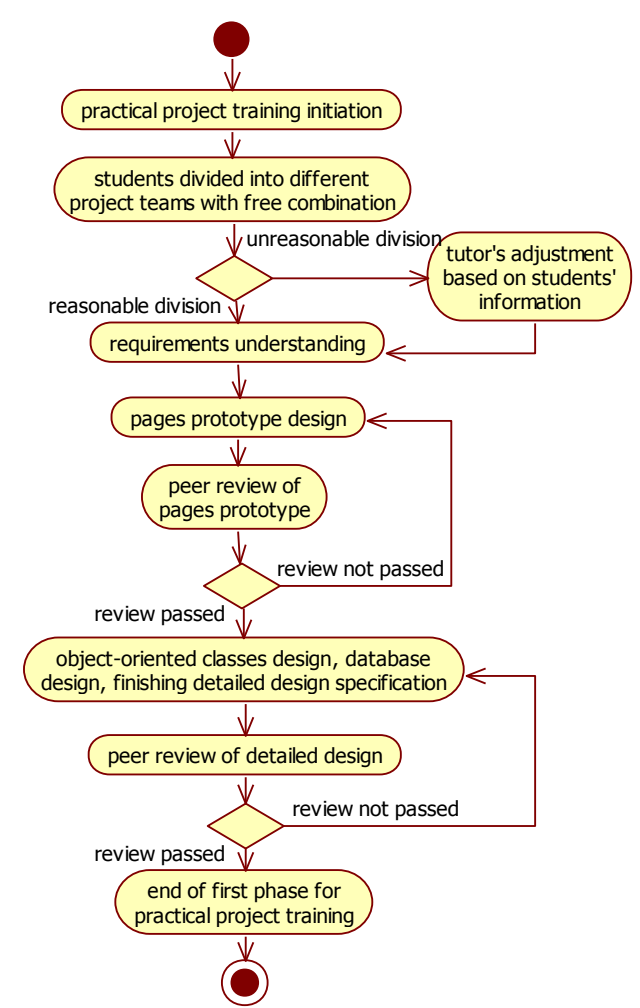

Figure2. First phase of practical project training.

In the step of practical project training initiation, tutors explain the whole training process and help students establish their self-confidence by a general understanding. After this step, all training students are divided into different project teams, which can be grouped by free combination or tutor's adjustment. The group is composed of team leader, configuration manager, review leader, database manager and test leader, which cooperates together to finish the project development. When the division is reasonable, requirements understanding of the formal training will start. Students are required to discuss every detail for the project in English. Because the selected project is based on the company's 
business, so the students have to understand what functions they will implement. Tutors will elicit key functions for each project, and lead each group to complete their requirements understanding.

With the full understanding of the requirements, students can design pages prototype with HTML, JavaScript and CSS or one visualization toolkit such as Visio. Here, we adopt the new peer review as the evaluation approach referenced by the company experience, that is, course group decides whether the achievements is qualified. Team leader of each group needs to present their deliverables in English. If the review is not passed, students have to modify the design and repeat the review process. If the review is passed, students can go to the next step of object-oriented classes design, database design and the detailed design specification writing. Similar to the previous review process, the achievements have to be reviewed by all tutors to decide whether the design needs modification. Except from presenting in English for each step, regular documents accordance with software development specifications are needed to complete in English for each group. This means students have to finish each deliverable referring to many resources. And they must cooperate with each other to finish these work.

The second part is shown in Fig.3.

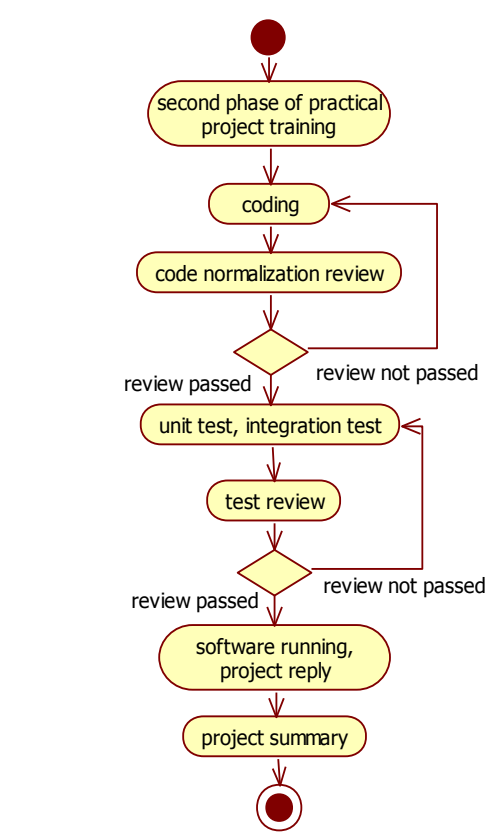

Figure3. Second phase of practical project training.

Although the students have put much emphasis on the coding step, tutors must put more energy into guidance or complete the work helped by the excellent students in part. Not only the required functions needs to be realized, but also the code normalization has to be reviewed. When complicated coding is finished, students need to test the units by themselves and test the integrated software using black-box method or some test toolkit such as LoadRunner. If the software is not qualified, students have to modify the code and test it again.

If the review is passed, students come to the final step of project reply and summary. In the final step, students can summarize what they have done in the whole training process and what they have learned and should improve in the future work.

In the whole process of practical project training, students are centered to complete the training process. We set different milestones at different review phase. Here milestone means the completion and delivery of all of the deliverables or other events which are included or described in the project plan scheduled for delivery or completion on a given target date. Our milestones include static pages and architectural framework, database design specification, source code, test report and project summary report. Each project team of the students must finish all the peer review process and deliver all the deliverables. Every step is completed based on their deliverables and presentations. Tutors only lead to finish these steps and review what they have finished.

\section{B. Teaching Approaches}

In bilingual training process, we not only give full play to theory teaching but also explore the effective teaching mode actively. In view of different study phase, we choose different practice content to motivate the students' interest, which can develop the students' team cooperation and innovation. After the training, students can solve the practical problem using the integrated knowledge and finish the formal development documents, which can help them in adapting to the job position quickly.

The main feature of our teaching approaches can be summarized as communicative teaching methods, hierarchical teaching and team cooperation. 
(1) Communicative teaching methods. Teaching English in communicative teaching methods help students improve their language application capability at a large extent from listening and speaking skill to enthusiasm and initiative. Introducing CTM into bilingual teaching for employment-oriented IT experience training program with too much theory and practice will not only broaden student's professional vocabulary, but also improve students' skills of listening, speaking and writing ability to express professional knowledge in English.

(2) Hierarchical teaching, which embodies the students' selection, teaching content and evaluation method. We divide the selected students into different teaching class based on their practical ability and choose different framework knowledge. For the low level students, the corresponding evaluation is much easier compared to the high level students.

(3) Team cooperation, which can be embodied in the process of practical project training. The project team has to finish the complete requirements understanding, pages prototype design, detailed design, coding and testing as a whole. Only one member can hardly finish the work. To cooperate with other members, students must express their ideas in English and communicate with different kinds of people.

\section{CONCLUSIONS}

The key orientation of nationalities universities is to promote employment rate of the undergraduates. So setting up bilingual employment-oriented IT experienced training curriculum in these universities is urgent and necessary. In the 2009 teaching outline of Dalian Nationalities University, experienced training course has been scheduled as the elective course for the undergraduates with computer science as major.

In this paper, we summarize bilingual training experiences of the software company and compare training advantages and disadvantages between software companies and university. So it is necessary to set up bilingual employment-oriented IT experienced training curriculum in nationalities universities. Based on experiences of the first experimental project in our university and bilingual training experiences of authors from New Zealand, we put forward a feasible bilingual training system, which the concrete implementation process, teaching organization method and evaluation methods are discussed in detail.

The innovative points of the training program are bilingual training process design and peer review evaluation. Three flowcharts explained the main idea of our training design and peer review completed by tutors of the course group embodied the importance of the team cooperation and deliverables in English of each phase.

With more experimental project and accumulated experiences, our bilingual employment-oriented IT experienced training will play more and more important role in enhancing students' language application ability, professional skill training, developing students' project practical ability and communication and expression ability. Through our bilingual training program, employment competence of graduates from nationalities universities especially for international talents will be promoted a lot in the future.

\section{REFERENCES}

[1] Collins, M. (2006). Industry-oriented software education in practice: a case study. Proceedings of 2nd China-Europe International Symposium on Software Industry-Oriented Education, 78 - 82.

[2] Qin Z. G., Xia Q., Lei H. (2007). Training software engineering talents: exploration and practice. Acta Scientiarum Naturalium Universitatis Sunyatseni 146.12, 142-143.

[3] Collins, M. (2007). Experiences in industry placement-shaping the student's Mind in an industry-oriented software engineering curriculum. Acta Scientiarum Naturalium Universitatis Sunyatseni 146.12, 83-85.

[4] Liu S., Li X. Z., Chen P. (2010). Research on Employment-Oriented IT Experience Training Program: Computer Education 9, 140-143.

[5] Edenz Colleges. TESOL Certificate Course. http://www.edenz.com/Page.aspx?id=28( accessed 12/11/2010).

[6] Roger S. Pressman (2005). Software Engineering: A Practitioner's Approach (6th edition). Boston, MA: McGraw Hill Higher Education.

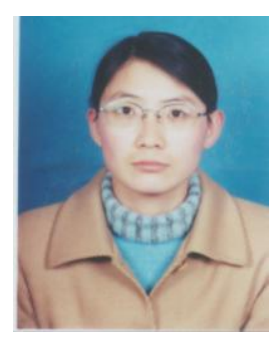

Shuang Liu, born in Jinzhou, Liaoning, China, received her Ph. D degree of Traffic Information Engineering \& Control from Dalian Maritime University in 2006.

She currently works as an Associate Professor at the college of computer science \& engineering, Dalian Nationalities University, Dalian, China. Her research interests include computer education, intelligent transportation system and machine learning algorithms. Her academic papers are published both national and international conferences such as High Technology Letters (2006), Lecture Notes in Computer Science 5263 (2008) and Proceedings of the Fifth International Conference on Machine Learning and Cybernetics (2006). She is also a review expert for the Journal of Systems Engineering and Electronics and the 2010 International Conference on Computer Application and System Modeling.

Dr. Liu is a member of WASE (World Association of Science Engineering) with number WASE0000257. 


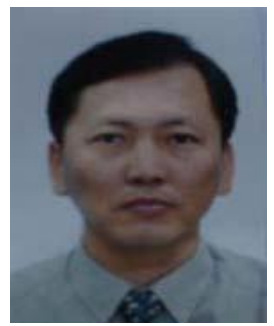

Xizuo Li was born in Jiaohe, Jilin, China. He is currently a professor and vice president in the college of computer science \& engineering of Dalian Nationalities University. His interests include computer education, workflow models and e-learning.

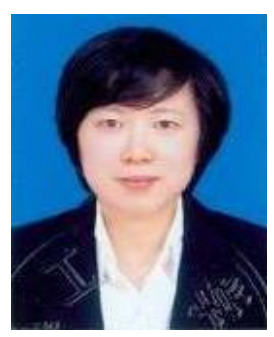

Li Zuo, corresponding author, was born in Dalian, Liaoning, China in 1975. She received her PhD degree of Technological economic management from Dalian University of Technology in 2009. Her research interests include project management and high technology industrialization. 